\title{
Using GIS to Plan Specialty Health Services for Veterans: The Example of Acute Stroke
} Care

\author{
Diane C. Cowper Ripley ${ }^{1}$, Eric R. Litt ${ }^{1}$, Huanguang Jia ${ }^{1}$, Walter Bruce Vogel ${ }^{1}$, Xinping Wang1, \\ Lauren K. Wilson', Michael S. Phipps², Jo Ann Harner ${ }^{3}$, Glenn D. Graham ${ }^{4}$ \\ ${ }^{1}$ HSR\&D/RR\&D Center of Innovation on Disability and Rehabilitation Outcomes, Gainesville, USA \\ ${ }^{2}$ University of Maryland, Baltimore, MD, USA \\ ${ }^{3}$ University of New Mexico, Albuquerque, NM, USA \\ ${ }^{4}$ Specialty Care Services (10P4E), Department of Veterans Affairs, Washington DC, USA \\ Email: Diane.Cowper2@va.gov
}

Received 17 April 2014; revised 10 May 2014; accepted 20 May 2014

Copyright (C) 2014 by authors and Scientific Research Publishing Inc.

This work is licensed under the Creative Commons Attribution International License (CC BY).

http://creativecommons.org/licenses/by/4.0/

(c) $\underset{\mathrm{EY}}{\mathrm{Br}}$ Open Access

\section{Abstract}

The Department of Veterans Affairs (VA) manages the largest healthcare system under a single management structure in the United States. Providing access to high quality healthcare to the VA's nearly 9 million enrollees is a mission priority for the Veterans Health Administration (VHA), the arm of the VA that oversees all medical facilities and operations. Geographic Information Systems (GIS) tools enable analysts to construct data-driven recommendations to policy makers for providing the best and most timely healthcare to those individuals who have honorably served their country. This paper illustrates how GIS is being used by the VHA and provides the example of acute stroke care access for Veterans in one Veterans Integrated Service Network (VISN) within the VHA.

\section{Keywords}

Veterans, Stroke, VA, Access, Healthcare

\section{Introduction}

Stroke is a leading cause of death and long-term disability in the United States [1]. Its high prevalence and associated neurological deficits impose a large burden on patients, their families, and the health care system. This is especially true among the elderly, where cerebrovascular diseases (stroke and transient ischemic attacks) are the 
second leading cause for hospitalization. Among patients hospitalized with stroke, two-thirds are over age 65, and half are over age 70 years. With an increasing incidence of stroke combined with a growing elderly population, the absolute number of people with stroke will continue to increase in the coming decades.

"Time Lost is Brain Lost" is a motto adopted by the American Stroke Association to emphasize the importance of providing timely and appropriate care for people who are experiencing symptoms of a stroke [2]. Both the National Institute of Neurological Disorders and Stroke and the Advanced Cardiac Life Support guidelines recommend "door to treatment" of one hour to reduce the odds of serious impairment or death for persons who are candidates for thrombolytic therapy [3] [4]. The most commonly used drug for thrombolytic therapy is tissue plasminogen activator (tPA). "The sooner tPA is given to patients, the greater the benefit. Every 10 minutes in which therapy is delayed, one fewer of each hundred treated patients benefits" [5]. Further, tPA can only be administered 3 to 4.5 hours after stroke onset. Thus, travel time to medical facilities is critically important for the treatment of this particular disease.

The Veterans Health Administration (VHA) manages the largest health care system under a single management structure in the United States. There are nearly 9 million Veterans who are enrolled in the VHA, representing about $40 \%$ of all US Veterans. The VHA is divided into 21 Veterans Integrated Services Networks (VISNs) that deliver health care to eligible Veterans in their region. Each year, there are approximately 6000 patients nationally who are admitted to a VHA hospital with a stroke [6]. Travel time is especially important within the VHA since a limited number of VHA health care facilities must serve a Veteran population that is widely dispersed throughout the US. Veterans often travel a great distance to VA Medical Centers for healthcare services.

\section{Objectives}

The objectives of this study were to explore both historical access and possible future access to stroke care under varying expansion scenarios. To measure historical access, our first objective sought to identify VA enrollees diagnosed with acute stroke over a five year period and to ascertain their access (travel time) to VHA and non-VHA hospitals with acute stroke care capabilities. To examine possible future access to stroke care, our second objective examined the population of VHA enrollees 65 years of age and older as the group of veterans at highest risk of stroke. This research received approvals from the Institutional Review Board at the University of Florida and the Research and Development Committee at the North Florida/South Georgia Veterans Health System in Gainesville, Florida.

\section{Methods}

\subsection{Design}

This is a retrospective, observational, secondary database study.

\subsection{Data}

All VA Medical Centers providing emergency medical services required to submit plans for delivery of acute stroke care. The facilities could self-designate as providing stroke care in one of three levels: Primary Stroke Center (PSC); Limited Hours Stroke Facility (LHSF); or Supporting Stroke Facility (SSF). Only PSCs and LHSFs are capable of providing acute stroke care; the former at all times, the latter only during pre-specified hours. Each type of facility was geo coded by exact address.

VHA enrollees who were aged 65 and older in fiscal year (FY) 2010 were identified from VHA online ProClarity data cubes managed by VHA Service Support Center (VSSC). The number of eligible enrollees was tallied by their ZIP code of residence for each Veterans Integrated Service Network (VISN), as well as for the nation.

We identified the VHA enrollees who were hospitalized for an acute stroke during FY2006 through FY2010 in the VHA Medical SASTM Patient Treatment File (PTF) by using the International Classification of Diseases, Ninth Revision, Clinical Modification (ICD-9-CM) stroke codes of 431, 432, 433, 434, 435, 436, and 437. The PTF contains demographic (e.g., sex, race, marital status, date of birth, age, period of military service, and state, county and Zip code of residence) and summary information about each inpatient episode (e.g., hospital where care took place, date of admission, number of diagnoses, number of bed sections, number of procedures segments, number of operations, the diagnosis responsible for length of stay, and secondary diagnostic codes for 
co-morbidities, length of stay, and discharge status, including death). This file is accessible to VA researchers with appropriate clearance, and Institutional Review Board and Research and Development Committee approvals. The patients' residence ZIP codes were extracted from the PTF and aggregated by VISN. Geographic information (address) on all non-VHA Stroke Centers was also obtained from VA Central Office and geocoded.

\subsection{GIS Techniques}

The Geographic Information System (GIS) analyses included calculating the 15-, 30-, 45-, 60-, and >60-minute round transportation travel bands from the enrollees' and stroke patients' residence ZIP codes to the various VHA and non-VHA acute stroke care facilities at the national and VISN levels. For the analyses focused on in this paper, we were interested in those Veterans who were more than a 60 minute travel time to acute stroke care. Travel times are weighted by population density and type of road; however, we did not account for traffic patterns at different times of the day (i.e., rush hour).All GIS analyses were conducted using the ArcGIS software version 10.1 from Esri in Redlands, California.

\subsection{What If? Scenarios}

For illustrative purposes, we selected out one VISN in the Southeast region of the United States. The same methods and analyses were conducted on all 21 VISNs across the country; however, due to space limitations, we present only a single VISN as an example of our application of GIS tools to this population. The number of stroke patients between FY2006 and FY2010 in our selected VISN was 742 and the number of FY2010 VHA enrollees 65 years of age and older was 194,295.

We produced maps depicting 1) enrollees who were admitted to a VHA facility with a stroke diagnosis from FY2006-FY2010 and 2) FY2010 enrollees aged 65 and older (highest “at risk” population for stroke) and their geographic distance from current VA Medical Centers with full acute stroke care capabilities (Primary Stroke Centers). These were the maps and stroke populations that formed the baseline from which we examined four alternative scenarios regarding stroke center availability.

Our four scenarios include 1) choosing a single VA Limited Hours Stroke Facility for upgrade to a VA Primary Stroke Center, 2) upgrading all VA Limited Hours Stroke Facilities, 3) establishing 3 partnerships with non-VA Primary Stroke Centers, 4) establishing partnerships will all non-VA Primary Stroke Centers, and 5) achieving maximum access by combining Scenarios 2 and 4, upgrading all VA Limited Hours facilities and establishing partnerships for all non-VA centers.

The first scenario reflected a constraint that policy makers could only upgrade one VA Limited Hours Stroke Facility to a VA Primary Stroke Center. Hot Spot analysis and Location-Allocation tools in ArcGIS Network Analyst were used to identify the VA candidate facility that maximized the increase in the number of enrollees and patients within a one-hour drive time to stroke care.

The second scenario assumed that all Limited Hours Stroke Facilities in the VISN were upgraded to Primary Stroke Centers and the increases in enrollee and patient within one hour of current Primary Stroke Centers and the newly upgraded Limited Hours Stroke Facilities were calculated. This was considered the maximum VHA-only expansion, as it is unlikely that a third-tier Supporting Stroke Facility would have the staff, expertise, physical capacity or financial resources to upgrade to a Primary Stroke Center.

Scenario 3 assumed that no upgrades to VHA facilities were possible and the only way to increase access to acute stroke care for Veterans was through partnerships with non-VA Stroke Centers. Hot Spot analysis and Location-Allocation tools in ArcGIS Network Analyst were again used to identify the 3l non-VHA candidate facilities that maximize the increase in the number of past stroke patients and current elderly enrollees within a one-hour drive time to acute stroke care. Subsequent analyses incorporated all non-VHA Primary Stroke Centers (Scenario 4). This was considered the maximum non-VHA approach to increasing access.

The final scenario assumed that all VA Limited Hours Stroke Facilities upgraded to Primary Stroke Centers AND all Non-VA Stroke Centers entered into partnerships with the VHA. This scenario presents the maximum acute stroke care coverage that is possible within the VISN.

\section{Findings}

A series of maps (Figures 1-5) were generated to provide a visual display of changing access, depending on the 
60 Minute Travel Time Around VHA Primary Stroke Care Veterans Integrated Service Network 7

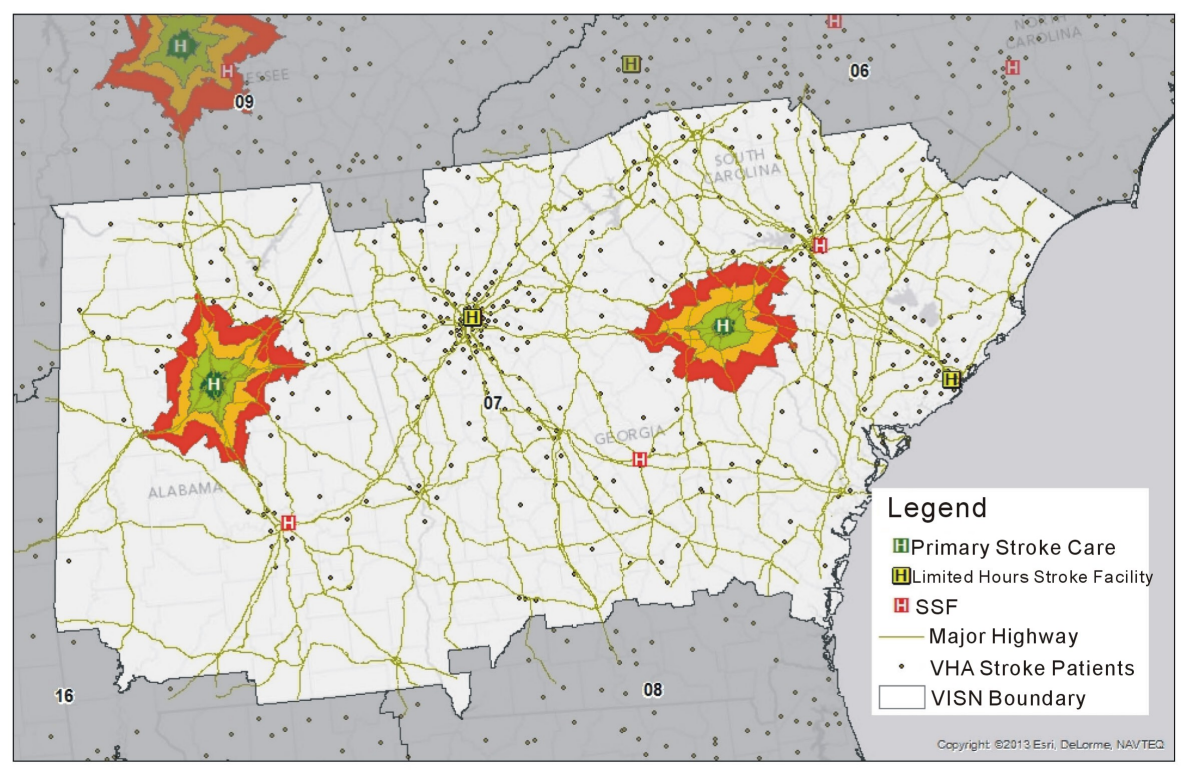

Figure 1. Access to VHA primary stroke care by Veterans who were hospitalized at VHA with stroke, VISN 7, FY06-FY10.

60 Minute Travel Time Around VHA Primary Stroke Care Veterans Integrated Service Network 7

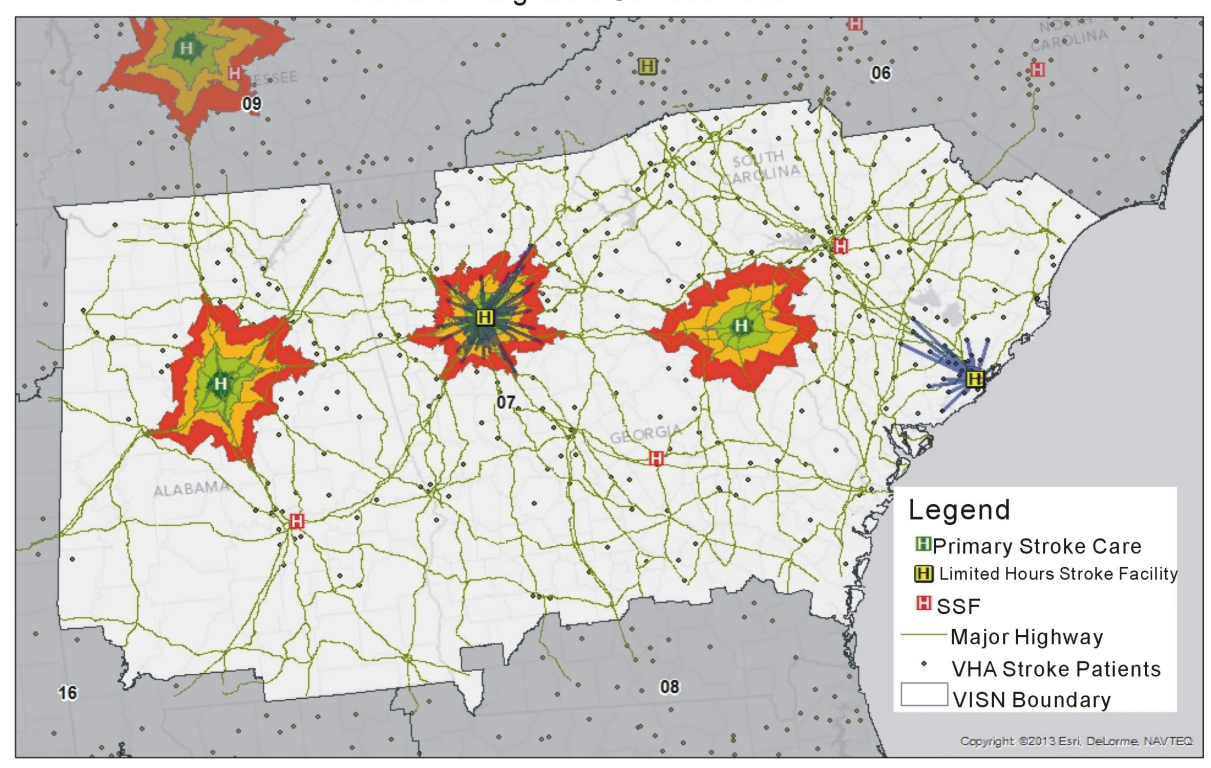

Figure 2. Acute stroke care access under Scenario 1.

scenario. In addition, numeric tables were constructed on how geographic coverage in each travel time category changed for each scenario tested (Table 1) for both retrospective stroke cases and the population at greatest future risk of stroke.

\subsection{Past Access to VA Acute Stroke Care}

Figure 1 graphically presents the location of the two VHA Primary Stoke Centers in VISN 7, along with the ZIP 
60 Minute Travel Time Around VHA Primary Stroke Care and Limited Hours Stroke Facilities (Maximum VA Capacity) Veterans Integrated Service Network 7

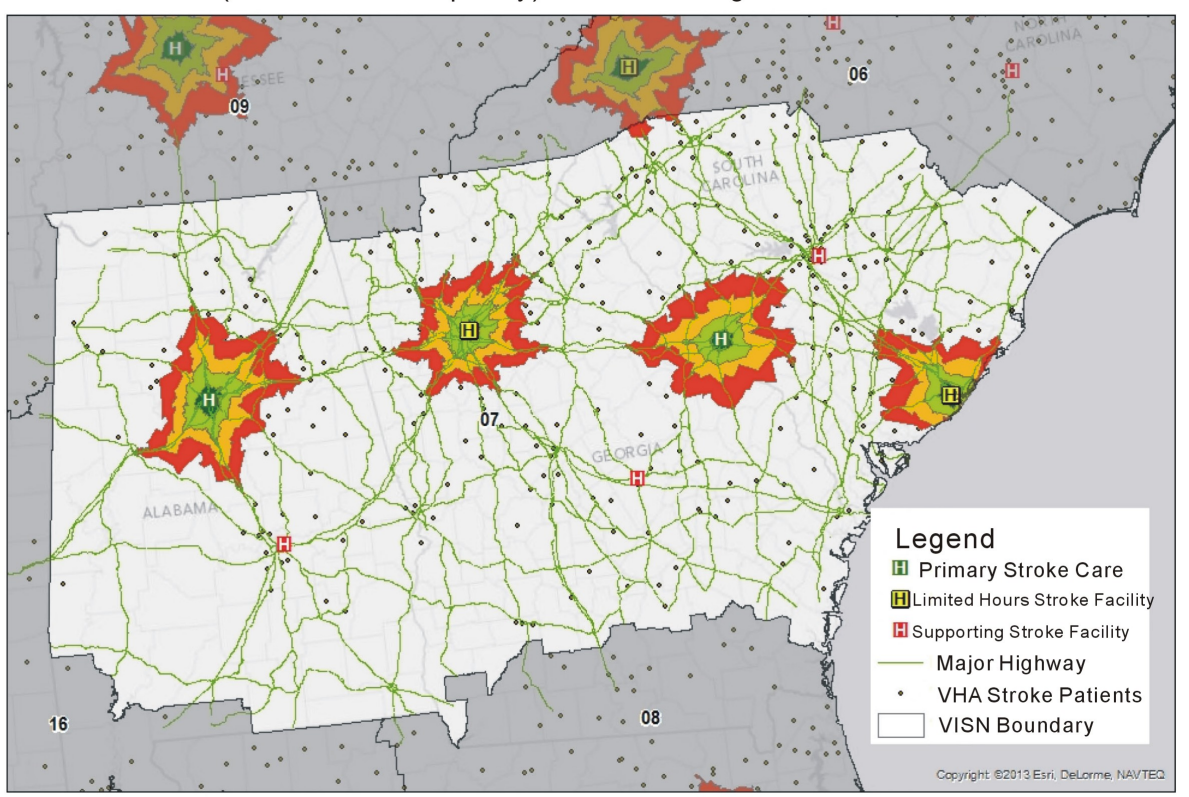

Figure 3. Maximum VHA acute stroke care coverage capability (Scenario 2).

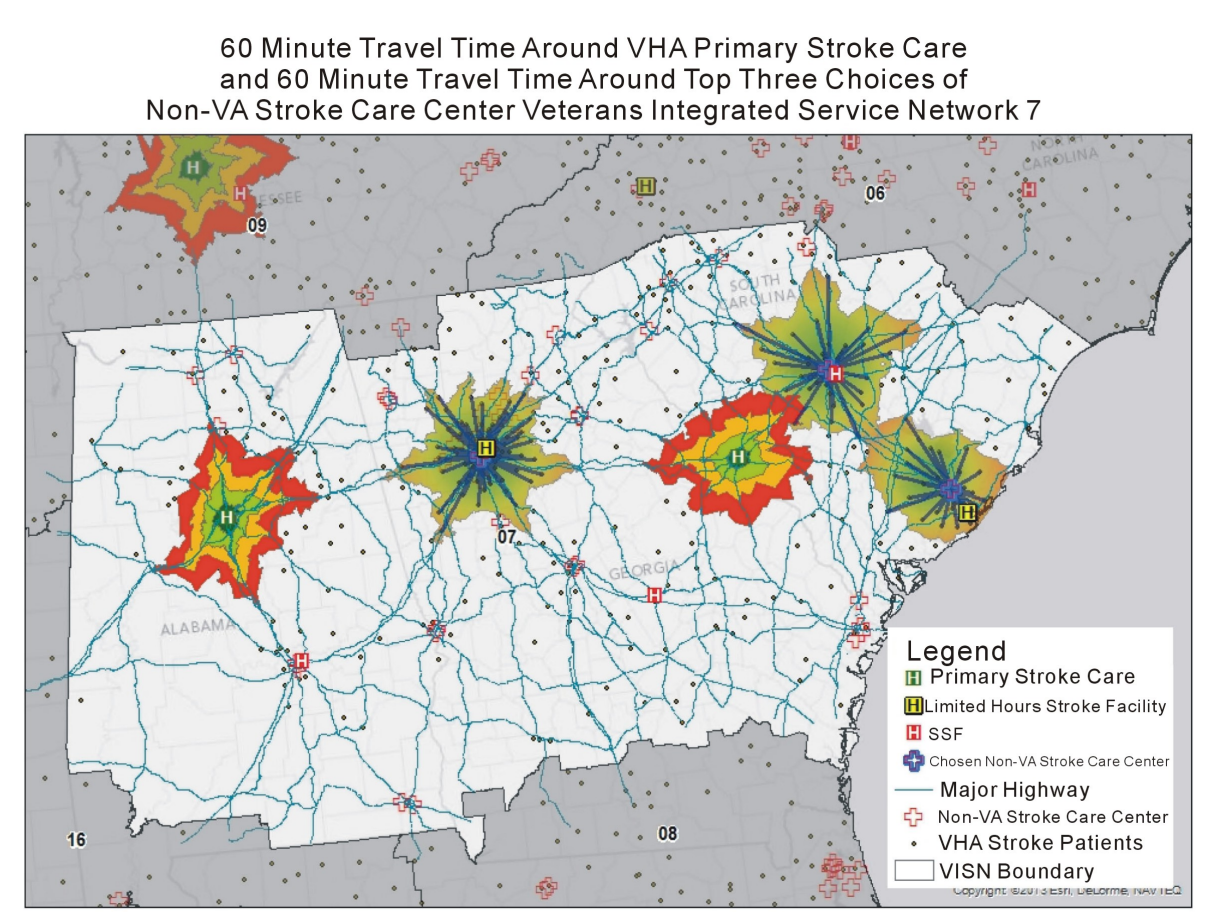

Figure 4. Acute stroke care access under Scenario 3.

code location where stroke patients from FY06 through FY10 resided. During this period, there were 742 patients with stroke identified through the Medical SAS inpatient databases using the ICD-9 codes listed in the previous section. The number of patients with stroke who were within the 60 minute travel time was 136, or $18.3 \%$.

Figure 2 shows the location-allocation results under the scenario that the VHA can only upgrade one VHA Limited Hours Stroke Facility to a VA Primary Stroke Center in VISN 7. The change in the percentage of pa- 
60 Minute Travel Time Around VHA Primary Stroke Care,

VHA Limited Hours Stroke Facilities and Non-VA Stroke Care

Facilities (Maximum Capacity in VISN) Veterans Integrated Service Network 7

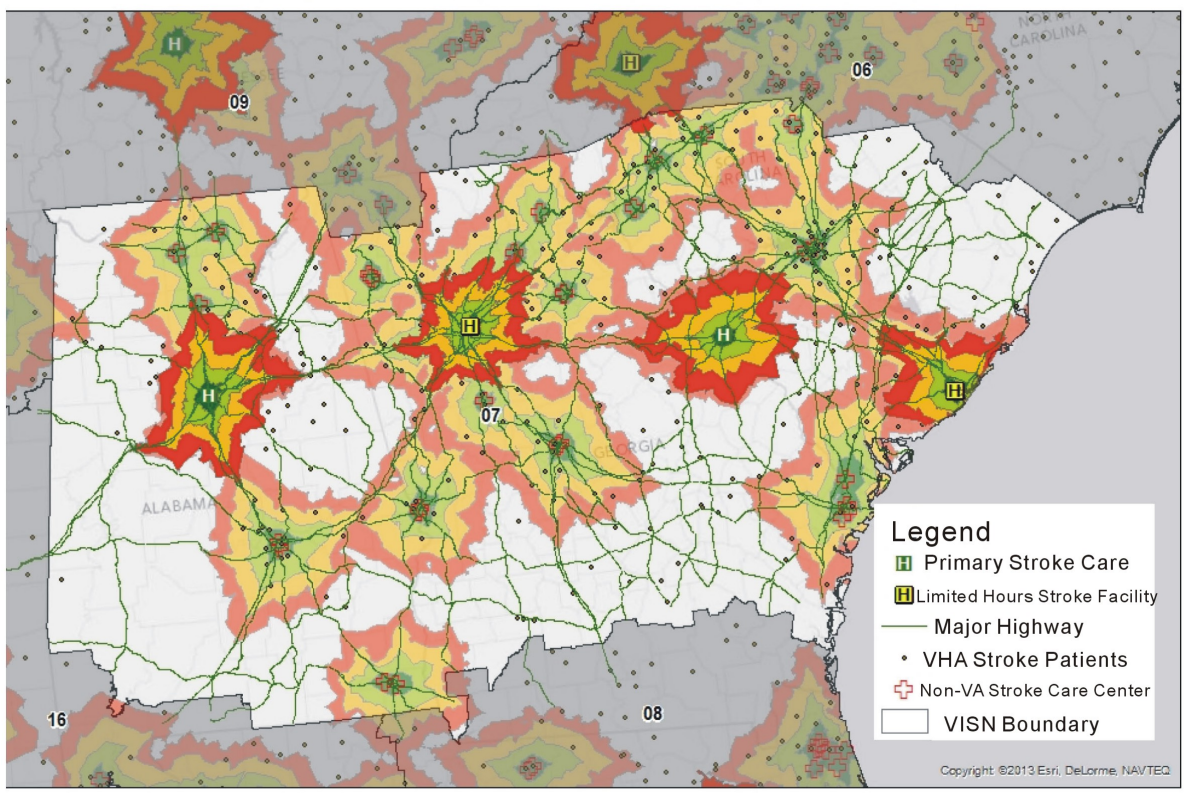

Figure 5. Maximum acute stroke care coverage capability in VISN (VA and Non-VA Sites).

Table 1. Number of stroke patients and enrollees $65+$ within 60 minutes of acute stroke care.

\begin{tabular}{|c|c|c|c|c|c|c|}
\hline \multirow{2}{*}{ Scenario } & \multicolumn{3}{|c|}{$\begin{array}{c}\text { Number of Stroke Patients within } 60 \text { Minutes of Acute Stroke } \\
\text { Care }\end{array}$} & \multicolumn{3}{|c|}{$\begin{array}{c}\text { Number of Enrollees 65+ within } 60 \text { Minutes of } \\
\text { Acute Stroke Care }\end{array}$} \\
\hline & Description & $\mathrm{N}$ & $\%$ & Description & $\mathrm{N}$ & $\%$ \\
\hline Baseline & $\begin{array}{l}\text { Stroke Patients FY06-FY10 within } 60 \\
\text { minutes of current VHA primary stroke } \\
\text { facilities }\end{array}$ & 136 & $18.3 \%$ & $\begin{array}{c}\text { FY2010 Enrollees 65+ within } 60 \\
\text { minutes of current VA primary } \\
\text { stroke facilities }\end{array}$ & 22,076 & $11.4 \%$ \\
\hline 1 & $\begin{array}{c}\text { Stroke Patients } \\
\text { FY06-FY10 within } 60 \text { minutes of VA } \\
\text { primary stroke facilities + 1VHA limited } \\
\text { hour facility upgraded to primary } \\
\text { stroke facility }\end{array}$ & 273 & $36.8 \%$ & $\begin{array}{c}\text { FY2010 Enrollees 65+ VA within } 60 \\
\text { minutes of primary stroke facilities }+1 \\
\text { VA limited hour facility upgraded to } \\
\text { primary stroke facility }\end{array}$ & 47,615 & $24.1 \%$ \\
\hline 2 & $\begin{array}{c}\text { Stroke Patients } \\
\text { FY06-FY10 within } 60 \text { minutes of VA } \\
\text { primary stroke facilities + all VHA } \\
\text { limited hour facilities upgraded to } \\
\text { primary stroke facilities (Maximum } \\
\text { VHA capacity) }\end{array}$ & 339 & $45.7 \%$ & $\begin{array}{l}\text { FY2010 Enrollees 65+ VA within } 60 \\
\text { minutes of VA primary stroke facilities } \\
\text { + all VA limited hour facilities } \\
\text { upgraded to primary stroke cenerss } \\
\text { (Maximum VA capacity) }\end{array}$ & 56,607 & $29.1 \%$ \\
\hline 3 & $\begin{array}{c}\text { Stroke Patients } \\
\text { FY06-FY10 within } 60 \text { minutes of VA } \\
\text { primary stroke facilities }+ \text { top } 3 \\
\text { non-VHA Stroke Centers }\end{array}$ & 303 & $40.8 \%$ & $\begin{array}{l}\text { FY2010 Enrollees 65+ within } 60 \\
\text { minutes of VA primary stroke facilities } \\
\text { + top } 3 \text { non-VA Stroke Centers }\end{array}$ & 75,097 & $38.7 \%$ \\
\hline 4 & $\begin{array}{c}\text { Stroke Patients } \\
\text { FY06-FY10 within } 60 \text { of all VA and } \\
\text { all non-VA facilities (Maximum } \\
\text { capacity in VISN) }\end{array}$ & 615 & $82.9 \%$ & $\begin{array}{c}\text { FY2010 Enrollees 65+ within } 60 \\
\text { minutes of all VA and all non-VA } \\
\text { facilities (Maximum capacity in VISN) }\end{array}$ & 145,700 & $75.0 \%$ \\
\hline
\end{tabular}

tients with stroke who are within 60 minutes of acute stroke care doubles from approximately $18 \%$ to $36 \%$ with this single upgrade.

Since there are two Limited Hour Stroke Facilities in VISN 7, Figure 3 illustrates the results from the scena- 
rio where the VHA is able to upgrade all VHA Limited Hour Stroke Facilities to VHA Primary Stroke Centers. This is the maximum VHA stroke coverage capacity, and results in $45.7 \%$ of past stroke patients who would have been within 1 hour of acute stroke care if the Limited Hours Stroke Facilities had been 24/7 Primary Stroke Centers.

If the Limited Hour Facilities in this VISN could not be upgraded due to staffing or other resource difficulties, one way to increase coverage would be through partnerships with non-VHA medical facilities that could provide the appropriate level of acute stroke care. In Figure 4, the VHA Primary Stroke Centers remain, but the top 3 candidates non-VHA Primary Stroke Centers in term of access coverage.

Our final scenario makes all VHA Primary Stroke Centers, VHA Limited Hours Stroke Centers and all non-VHA Primary Stroke Centers available to the past VHA stroke patients. Scenario 4 is considered the maximum acute stroke access coverage in VISN 7. The new coverage area is displayed in Figure 5 and represents approximately $83 \%$ coverage.

\subsection{Future Access to Acute Stroke Care for Elderly Veterans}

In FY2010, there were 194,295 VHA enrollees residing in VISN 7 who were 65 years of age and older. We replicated the maps and analyses for this “at risk” population, from baseline (existing VHA Primary Stroke Centers) to the maximum (VHA and non-VHA Primary Stroke Centers in VISN 7). The results are presented in Table 1. At baseline, the percent of FY2010 enrollees over the age of 65 who lived with 60 minutes travel time of acute stroke care was $11.4 \%$. The number and percent coverage increased for each scenario, with the maximum access coverage of 145,700 (75\%) enrollees within a 60 minute travel time if VHA Primary Stroke Centers, all VHA Limited Hours Stroke Facilities and all non-VHA Primary Stroke Centers are equipped to treat patients suffering from an acute stroke.

\section{Discussion}

Treatment of acute-stroke patients in stroke centers increases the odds that patients receive tPA and decreases stroke complications and morbidity. By determining the Veteran population with access to VHA Primary Stroke Center level care, identifying gaps, and providing data on how to implement and optimize care system-wide, recommendations can be made to improve VHA inpatient stroke access, care and outcomes.

It is unrealistic to mandate the VHA health care system, as it currently is configured, to provide acute stroke care within 60 minutes to all enrolled Veterans who may suffer a stroke. As can be seen in Table 1, even under the maximum capacity of both current VHA and non-VHA systems, the percentage of past VHA stroke patients that were within 60 minutes over would be approximately 83\%. For the FY2010 enrollees 65 years of age and older who are at the highest risk of stroke, the maximum coverage capacity was 75\%. These percentages represent the practical upper limits on 60-minute access in this VISN.

Expanding access coverage relies on many factors. In an era of ever-shrinking budgets and resource availability, decisions of "build or buy” become increasingly important. In particular, the marginal cost of each of the expansion scenarios examined here is critical to determining which scenario is most cost-effective. New and creative alternatives to filling in access gaps to specialty care are being considered and may dramatically change the cost-effectiveness landscape for stroke care. One option that the VHA is exploring is using tele-health for specialty care in VHA medical centers and community based outpatient clinics that currently do not have that capacity.

\section{Conclusion}

GIS tools are an essential part of the planning process and can provide decision makers with data-driven recommendations as to where resources could be placed to make the maximum impact on reducing geographic access barriers, either through expanding VHA capacity, building relationships with non-VHA community partners, or optimally placing tele-health equipment for specialty care.

\section{Acknowledgements}

This research was supported by the Quality Enhancement Research Initiative (QUERI), Health Services Research and Development, Office of Research and Development, Department of Veterans Affairs as grant number 
RRP-10-197. The views and opinions expressed in this paper are those of the authors and do not necessarily represent those of the Department of Veterans Affairs, Health Services Research and Development or the QUERI program.

\section{References}

[1] Roger, V.L., Go, A.S., Lloyd-Jones, D.M., et al. (2012) Heart Disease and Stroke Statistics—2012 Update: A Report from the American Heart Association. Circulation, 125, e2-e220. http://dx.doi.org/10.1161/CIR.0b013e31823ac046

[2] American Stroke Association http://www.strokeassociation.org/STROKEORG/AboutStroke/TypesofStroke/TIA/Why-Rush-TIA-is-an-Emergency UCM 310729 Article.jsp

[3] The ATLANTIS, ECASS and NINDS r-t-PA Study Group Investigators (2004) Association of Outcome with Early Stroke Treatment: Pooled Analysis of ATLANTIS, ECASS, and NINDS rt-PA Stroke Trials. The Lancet, 363, 768-774. http://dx.doi.org/10.1016/S0140-6736(04)15692-4

[4] Field, J.M., Hazinski, M.F., Sayre, M.R., et al. (2010) Part 1: Executive Summary: 2010 American Heart Association Guidelines for Cardiopulmonary Resuscitation and Emergency Cardiovascular Care. Circulation, 122, S640-S656. http://dx.doi.org/10.1161/CIRCULATIONAHA.110.970889

[5] Lansberg, M.G., Bluhmki, E. and Thijs, V.N. (2009) Efficacy and Safety of Tissue Plasminogen Activator 3 to 4.5 Hours after Acute Ischemic Stroke: A Metaanalysis. Stroke, 40, 2438-2441.

[6] Stroke QUERI Fact Sheet (2012) http://www.queri.research.va.gov/about/factsheets/stroke_factsheet.pdf 
Scientific Research Publishing (SCIRP) is one of the largest Open Access journal publishers. It is currently publishing more than 200 open access, online, peer-reviewed journals covering a wide range of academic disciplines. SCIRP serves the worldwide academic communities and contributes to the progress and application of science with its publication.

Other selected journals from SCIRP are listed as below. Submit your manuscript to us via either submit@scirp.org or Online Submission Portal.
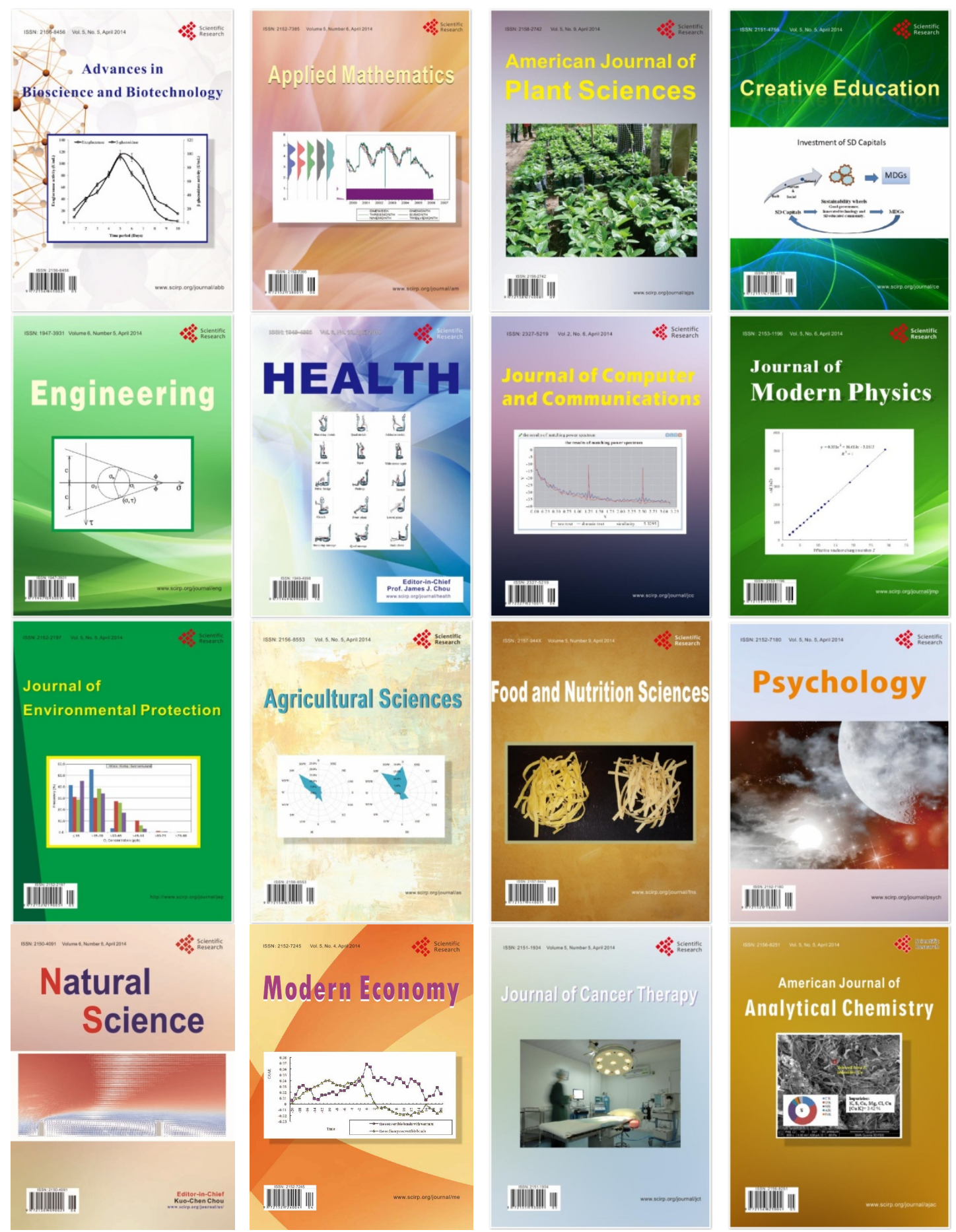